\title{
Do Narcissists Tend to Reduce Interpersonal Conflicts in Organizations? The Effects of Abusive
} Supervision on Ostracism and Interpersonal Conflicts

\author{
Tahira Rasheed ${ }^{1}$, Arshad Zaheer², Sadaf Manzoor ${ }^{3}$ \\ ${ }^{1}$ National University of Modern Languages, Islamabad, Pakistan \\ ${ }^{2}$ Pakistan Institute of Engineering and Applied Sciences, Pakistan \\ ${ }^{3}$ School of Leadership, Riphah International University Islamabad, Pakistan \\ tahirarasheed84@gmail.com, arshadzaheer@pieas.edu.pk, sadafmanzoor555@gmail.com
}

\begin{abstract}
This study aims to examine the relationship between abusive supervision (ABS) and interpersonal conflicts (IPC) with the mediating role of key variables, ostracism (OST), and moderating role of narcissism (NAR) among the service industry of Pakistan. A convenient sampling technique is used for data collection from employees of public and private commercial banks of Pakistan through a self-administered questionnaire. A total of 650 questionnaires were distributed with a response rate of $38 \%$, as 247 valid responses were received. The findings validated the proposed model with a significant correlation between ABS and OST, provoking IPC in organizations. The mediating role of OST is examined. Full mediation between ABS and IPC is revealed. Moreover, a subordinate's NAR moderated and weakened the positive relation of ABS and OST and OST and IPC. This study will help employers devise a methodology to minimize IPCs among employees after discovering the reasons for conflicts among them. One reason specified by this theory is ABS. Employers can look upon this study to mitigate conflict in their organization, hampering their strategies to progress. Eventually, this study will contribute to reducing a major threat of the organizations where their manpower is enforced towards burnouts due to the factors discussed here.
\end{abstract}

Keywords: Abusive supervision, ostracism, interpersonal conflicts, narcissism, sociometry theory, selfdetermination theory.

\section{Introduction}

During the last two decades, huge-sized business organizations came into prominent existence in the global scenario. This situation has created a need to focus on skilled and motivated human resources rather than increasing the workforce because it has become very costly with the industrial boom in Europe, Asia, and America. Therefore, the concept of happy employees is very successful in increasing the productivity of industries. Additionally, with the advent of a new era, there has been tremendous research on the effects of leadership styles on employees. A large amount of empirical research is available on the positive impacts of leadership on employee attitudes, behavior, and psychological health. The survival of business in today's highly competitive and adaptive ambiance is inevitable for those firms who are more productive and ready to accept the challenges of the modern world. This globalization of business is subject to vigorously changing customer demands and an ever-increasing high level of satisfaction. To meet such targets of customer satisfaction, the leading organizations in service industries have modified and enhanced their business processes and service delivery channels. Hence, orthodox administrative and supervision methodology is no longer an unexpected and successful methodology. Likewise, the stimulus of violent supervisory methodology, practiced in one of the service industries like the banking sector of Pakistan, has not been considerably studied.

It is unfortunate because the banking sector of Pakistan constitutes 58\% of the service industries (Pakistan Economic Survey, 2015-2016) and contributes a considerable amount to GDP every year. Globally, services industries now occupy $60 \%$ of the global GDP as it serves millions of people worldwide (Pakistan Economic Survey, 2015-2016). So, in this context, any form of rude supervision needs to be examined as it may undermine the productivity of a valuable industry domestically and internationally. Experiencing mistreatment at work is an unfortunate reality for many employees. Mostly angry and dissatisfied customers show abusive behavior (Schat, Desmarais \& Kelloway, 2006; Greenbaum, Mawritz, and Quade, 2017). There is also substantial, empirical, and anecdotal evidence to suggest that employees often deal with oppressive and abusive supervisors. This unmannerly rude behavior of the supervisor denotes subordinate's perceptions of the extent to which supervisors are engaged in the sustained display of hostile verbal and nonverbal behaviors, excluding physical interaction (Tepper, 2000; Valle, Kacmar, Zivnuska \& Harting, 2018). Examples 
of behavior described by this definition include invasion of privacy, public ridicule, angry tantrums, shouting, and coercion (Malik, Shahzad \& Waheed, 2020).

Additionally, the consequences of ABS are significant for establishments and workforces alike. For instance, supervisor's aggression has been linked with decreased career contentment and executive obligation (Schat et al., 2006; Greenbaum et al., 2017), reduced business output (Valle et al., 2018), and increased turnover and absenteeism (Tepper, 2000; Kluemper, Mossholder, Ispas, Bing, Iliescu \& Ilie, 2018). Past research has also connected ABS to juniors' divergent conduct (Kohli, \& Mitchell 2007; Wang, Du, Yu, Meng \& Wu, 2020) and underprivileged emotional comfort (Mitchell \& Ambrose, 2007; Yagil, 2006; Mackey, Frieder, Brees, \& Martinko, 2017). So, personnel who work for unmannerly supervisors are inclined to be less content, less productive, and less vigorous, and subsequently, organizations perform less effectively. Recent research has also posed significant importance on the relatively destructive and darker side of leadership that has emerged from emotional exhaustion or the highly impulsive nature of the supervisors (Lam, Walter, Huang; 2017, Carson, Hoobler, \& McAllister; 2017; Leary, Tambor, Terdal \& Downs; 1995). One of the destructive practices of leadership is ABS, which is examined in this study. Research also suggests that abused workers somewhat consider their institute responsible.

For their supervisor's disregard, belittle, or ruthless behavior (Tepper, 2000; Schyns, Felfe \& Schilling, 2018). Literature has considerably illustrated the destructive outcomes of invasive direction for subordinates' psychosomatic comfort and performance productivities (Krasikova, Green \& LeBreton, 2013; Mackey et al., 2017). Consequently, abused workers tend to suppress categorical behavior in favor of the organization. The reason is depression, frustration, and anxiety caused by ABS (Haggard, Robert \& Rose, 2011; Mackey et al., 2017). A similar situation prevails in public and private organizations of Pakistan. In organizations, the abusive behavior of supervisors is considered normative. Abused workers are not supposed to indulge in any revenge activities (Al-Hawari, Bani-Melhem, \& Quratulain 2020; Wang et al., 2020). As a result, they develop a self-defensive mechanism like OST, leading towards worst outcomes like IPC among workers. In Pakistan, the primitive administrative styles and outdated policies stimulate the employees and organizations towards counterproductive work behavior. It is also one of the reasons for decreased employee vigor and enthusiasm towards their work responsibilities. As a result, employees and the organization fail to survive and confront the global market competition due to lower productivity. Ultimately, this results in a loss of already scarce resources.

A plethora of research has also suggested that a new generation of workers will be primarily diverse from the preceding one for their demands and expectations at work. This new generation feels more entitled and expects better treatment at work than others (Smola \& Sutton, 2002). The psychological entitlement was found productive in a survey conducted by Smola and Sutton (2002). This sense of entitlement invigorates a higher self-efficacy that is useful to confront any hostile or unpredictable situation in a better way. These employees are resilient at nerves and have such qualities that are inevitable to face any unexpected situation. This sense of entitlement is often at its peak as NAR admiration, which is also the construct of interest in the present study. NAR is well-defined by magnificence, relational demoralization, empathic troubles, and a sense of entitlement (Holtzman, Vazire \& Mehl, 2010). This construct, NAR, captivates the interest of a layman and a researcher alike due to its negative and positive facets at the same time. Narcissists incline to display outbound and affable performances that are to harvest them an optimistic first impression. They also lean towards display self-centered and unkind actions that are likely to get them into struggle (Reina, Zhang \& Peterson, 2014; Cheshure, Zeigler \& Sauls, 2020; Dong, Wen, Zhang, Fang, 2020).

Following the incongruent societal significances, narcissists are "disagreeable extroverts" (Furnham, Richards \& Paulhus, 2013). So, accordingly, the purpose of the present study is threefold: (1) the author has strived to reveal the effect of hostile supervisory methodology on employees' work behavior (2) how OST threatens the four fundamental human need: need to belong, need for high self-esteem, the need for self-control on one's social needs and need for a meaningful existence; and (3) author will deduce the implications for not considering narcissists always as a social evil and threat for organizations but at times they may be a fruitful group of individuals in the form of narcissists admiration in a hostile situation as a moderator and this aspect has revealed in past literature. Various authors have also studied the impact of narcissistic admiration as a moderator on personnel self-esteem (Fatfouta, Zeigler \& Schroder 2017; Reina et al., 2014, Furnham et al., 
2013). But the moderating effect of NAR between ABS and OST, between OST and IPC, is rarely studied by past researchers. Similarly, there is little reference available in the past about the mediating role of OST between NAR and IPC. Therefore, this study contributes significantly to the current body of knowledge by testing these effects in the banking industry.

A convenient sampling technique is used to gather the statistics from commercial and scheduled banks of Pakistan. The population of interest for the current study comprised a staff of programmed local banks functional in Pakistan. The aggregate figure of workforces in public and private banks is 106659. It is also the estimated population size of the present study. After obtaining a list of operating banks from the State Bank of Pakistan (2019), the author applied a convenient sampling technique on the population to select a sample. Out of 34 commercial banks in Pakistan, the author has nominated the top 10 banks to collect data. They include NBP, HBL, UBL, MCB, Faysal Bank, Bank Alfalah, Standard Chartered Bank, Meezan Bank, Bank AlHabib, and Soneri Bank. Table 1 shows the distribution of respondents of this study among public and private sector banks of Pakistan.

Table 1: Distribution of Respondents among Public and Private Sector Banks

\begin{tabular}{|c|c|c|c|c|c|c|}
\hline \multicolumn{7}{|c|}{ Scheduled Banks Operating in Pakistan } \\
\hline & \multicolumn{3}{|c|}{ Public Sector } & \multicolumn{3}{|c|}{ Private Sector } \\
\hline & Nationalized & Specialized & Provincial & Privatized & Private & Total \\
\hline No. of Banks & 2 & 4 & 2 & 4 & 22 & 34 \\
\hline No. of Employees * & 14610 & 8235 & 4301 & 40467 & 39046 & 106659 \\
\hline \%age of Employees & 13 & 8 & 4 & 38 & 37 & 100 \\
\hline Sample Proportion & 232 & 148 & 125 & 116 & 29 & 650 \\
\hline $\begin{array}{l}\text { No. of Banks } \\
\text { approached }\end{array}$ & 1 & 2 & 1 & 2 & 4 & 10 \\
\hline No. of Respondents & 98 & 52 & 37 & 31 & 29 & 247 \\
\hline
\end{tabular}

Table 2: Demographics and Comparative Situation of Number of Banks and Branches in Pakistan (June 2017)

\begin{tabular}{|c|c|c|c|c|}
\hline Type of Bank & Banks & \multicolumn{2}{|c|}{ Branches } & \\
\hline 1. Pakistani Banks & 30 & \multicolumn{2}{|c|}{3,029} & \\
\hline i. Public Sector & 09 & \multicolumn{2}{|c|}{2,986} & \\
\hline a. Commercial & 05 & \multicolumn{2}{|c|}{2,360} & \\
\hline b. Specialized & 04 & \multicolumn{2}{|c|}{626} & \\
\hline ii. Domestic Private & 21 & \multicolumn{2}{|c|}{10,043} & \\
\hline 2. Foreign Banks & 04 & \multicolumn{2}{|c|}{10} & \\
\hline Variable & Category & \multicolumn{2}{|c|}{ Frequency } & Percentage \\
\hline \multirow[t]{2}{*}{ Gender } & Male & 119 & 48.8 & \\
\hline & Female & 128 & 51.2 & \\
\hline Age & 25 or below & 38 & 16.4 & \\
\hline
\end{tabular}




\begin{tabular}{|c|c|c|c|}
\hline \multicolumn{4}{|c|}{$\begin{array}{l}\text { Journal of Economics and Behavioral Studies (ISSN: 2220-6140) } \\
\text { Vol. 12, No. 6, pp. 43-58, December } 2020 \\
\end{array}$} \\
\hline \multirow[b]{4}{*}{ Education } & $26-30$ & 32 & 12.8 \\
\hline & $31-35$ & 16 & 6.4 \\
\hline & $\begin{array}{l}36-40 \\
41 \text { or above }\end{array}$ & $\begin{array}{l}80 \\
81\end{array}$ & $\begin{array}{l}32.0 \\
32.4\end{array}$ \\
\hline & Bachelors & 122 & 50.0 \\
\hline \multirow{4}{*}{ Monthly Earnings } & Masters & 99 & 39.6 \\
\hline & Others & 26 & 10.4 \\
\hline & Less than $20 \mathrm{k}$ & 18 & 7.2 \\
\hline & $\begin{array}{l}20-30 \mathrm{k} \\
31-40 \mathrm{k} \\
41-50 \mathrm{k} \\
51 \text { and above }\end{array}$ & $\begin{array}{l}24 \\
40 \\
90 \\
75\end{array}$ & $\begin{array}{l}9.6 \\
16.0 \\
37.2 \\
30.0\end{array}$ \\
\hline
\end{tabular}

Another perseverance of this study is to scrutinize the outcomes of ABS. One such negative phenomenon studied here is OST. For this purpose, we draw on Leary et al. (1995) sociometry theory. It posits that people are motivated to protect and enhance their self-esteem linked to achieving the desired results. OST is categorized as a subjective and perceived exclusion, disrespect, and ignorance or sometimes self-imposed isolation by the employee himself as a coping strategy. Also, this phenomenon of OST or social exclusion shortened the individual need for belongingness in particular (Gardner, Pickett, Jefferis, \& Knowles, 2005) ultimately increases psychological stress that results in a reduction in anti-social behaviors (Holtzman et al., 2010). This approach is consistent with the sociometry theory. The chief motive for choosing the banking industry is that banking and financial institutions have knowledgeable immediate employees. Their staff is engaged with a high-level of supervisors to improve their performance and achieve their targets. The banking industry staff is specialized that works under high pressure from hierarchies to maintain the service level. Being a highly specified and professional sector, a strict level of supervision is evident in this sector. Ultimately, any orthodox supervisory technique may also be manifested in this industry and easily captured by a research study. This cognitive has made the banking industry the most applicable division for the current study.

\section{Literature Review}

Abusive Supervision and Interpersonal Conflicts: Tepper (2007) has done a great deal of work in exploring sarcastic supervision and its consequences. The most common manifestation of destructive administration suggested by his work was supervisor nonphysical, belittle behavior. He examined many related terms like public ridicule and taking credit for subordinate's success. Tepper (2007) pointed out that the existing literature that addresses ABS is not well integrated as it overlaps with varying degrees of supervisor's behavior and lack of unifying theoretical framework. According to him, these problems can inhibit the development of knowledge in this significant area. He supported detailed research explaining and evaluating the pros and cons of the existing literature until that date. The study of Tepper (2007) has differentiated various forms of mocking surveillance, like generalized hierarchal abuse, petty tyranny, victimization, and workplace $\mathrm{ABS}$. He has also added valuable literature explaining the consequences of astringent scrutiny. For example, he argued, destructive outcomes may evolve from a supervisor's abusive behavior like subordinates' resistance and deviant behavior.

Subordinates' aggressive behavior, decreased performance contributions, and psychological distress (Ambrose \& Ganegoda, 2020). These deleterious outcomes lead to obstructions that result in arguing and conflicting with their fellow workers like IPC. All the stated destructive outcomes of insufferable supervision examined by these scholars have one thing in common. It leads to psychological distress in employees that causes a decline in performance outcomes and motivation to work (Malik et al., 2020). This literature has left one aspect uncovered how the abused workers tend to behave with their colleagues and peers, which is 
examined by this study. Based on this literature, the author may argue that abused, demotivated, less performing, and psychologically depressed individuals adopt a coping mechanism of conflicting with their fellow workers. These depressed employees are more prone to IPC than the other ones. So it is hypothesized: Hypothesis 1: Abusive supervision positively relates to interpersonal conflicts.

Abusive Supervision and Ostracism: Workplace OST refers to the extent to which an individual perceives that he is ignored or excluded by others in the workplace (Tepper, 2000; Williams \& Nida, 2011). Workplace expulsion is collaborative exploitation taken as adverse consequences on workers' decisiveness toward labor. Such consequences include inferior work gratification, advanced withdrawal intentions (Kidwell, Eddleston \& Kellermanns 2018; Ferris, Lian, Brown \& Morrison, 2014), condensed individual benefits, such as expressive tiredness and emotional suffering (Wu, Yim, Kwan \& Zhang, 2012). Due to the deleterious attitudinal bearing, workplace OST can be harmful to the structural efficacy of workers. Ostracized employees may decrease their assignation in citizenship behavior that values others separately or the institute jointly (Kidwell et al., 2018). However, examination studies propose that office OST can upsurge members' destructive conduct to advantage others and the work team, to be acknowledged (Wu et al., 2012; Kidwell et al., 2018). The findings of various studies recommend investigation of the circumstances in which workplace OST reduces workforce citizenship conduct. So far, numerous views have been taken into account to discharge the relationship between office OST and workers' voluntary work behavior in favor of his institution's benefit.

Emerging from the concept of self-regard hazard standpoint Ferris et al. (2014) speculated and established that when detested, team workers are exposed to lower self-worth and affianced lower in volunteer occupational commitment to be regular with their scarce self-assessments. Grounding on an assets exhaustion perception, Derfler, Pillutla, and Thau (2010) and Rudert, Janke, and Greifeneder (2020) reported, being ostracized drains members' supervisory possessions and indicates a lower level of commitment at work, and accordingly, less in-role behavior. Inconsistency with this cognitive, Derfler et al. (2010) also proposed that when an official is ostracized, the possibility of other work options motivates a response to disengage from the current relationship to pursue others. On the contrary, the adverse impressions of business place OST on institutional truthfulness and virtuous deeds will be insubstantial for workers with low apparent employment suppleness because those team members are less proficient in discovering replacements to mollify their belongingness desires. As recommended by social identity theory (Tajfel, 2010), when people are not satisfied with the position of social assemblage, they are abandoned by the social group when they feel they have attractive employment alternatives (or advanced alleged work flexibility) (Tepper, 2000).

According to self-determination theory (Deci \& Ryan, 2011), there are three spiritual essentials of a human: competence, relatedness, and autonomy. The hostile behavior of the supervisor threatens the psychological needs of employees. First, the belittle behavior of the supervisor suppresses the employees' ability to complete a task effectively. Thus, suppressing workers' sense of competence. Second, abused workers' sense of relatedness is reduced by humiliating and degrading them in front of others as they are not respected members of the association (Ferris, Brown \& Berry, 2008; Rudert et al., 2020). Third, facing ABS, the workers have to behave according to the aspiration of their hostile supervisor (Wu et al., 2012), minimizing the demean situation, subordinates' autonomy is damaged. So it is concluded accordingly that the absence of these needs is detrimental to the employees' perceived behavior. Dissatisfied psychological needs result in devastating emotional instability and frustration in workers, such as aggression and behavioral deregulation (Zhao, Peng \& Sheard, 2013; Williams \& Nida, 2011). Ultimately the deprived and frustrated subordinates are likely to show more controversial behavior like OST. Thus, suppressing the psychological needs of individuals by ABS results in isolation of the workers. Accordingly, it is hypothesized:

Hypothesis 2: Abusive supervision positively relates to ostracism.

Ostracism and Interpersonal Conflicts: Being secluded by co-workers and left out from the team is a heartthrobbing practice. Employees in the United States have officially described collective segregation (Ferris et al., 2014). OST at the workplace occurs on every occasion when an individual or group of individuals the "ostracized" disrespects to take actions that engross another operative the "ostracize" when it is accustomed and appropriate to do so (Robinson, O’Reilly \& Wang, 2013; Dong et al., 2020). OST is diverse from dynamic customs of impoliteness to other harassments, oppression, and regulatory exploitation in two primary 
methods (Ferris et al., 2008; Zhang, Xie, Xue, \& Xu, 2020). First, relegation is short in communicative strength. For instance, rejecting an outranked from a workgroup interface would be an elusive gesticulation paralleled to overtly admonishing him for dwindling to meet a cut-off date. Secondly, OST deals with uncertainty. Offenders can effortlessly rationalize their manners as benevolent, a conventional omission with no related unkindness. Even though exile is an elusive method of exploitation, rising indications have established that being deprived of a societal link either by an individual or a group results in injurious endings for the target (Robinson et al., 2013). Similarly, as recommended by the social identity theory, it is evident that conflicts arise as various groupings are existent within institutions (Ashforth \& Mael, 1989), when ethics, necessities, welfares, thoughts, and objectives depart, persons are apt.

To affect by others that can eventually deleteriously affect relational dealings (Barki \& Hartwick, 2004). Existing scholarly studies have investigated that alleged distinction is inter-connected to conflict (Barki \& Hartwick, 2004). Henceforth, clashes indeed ascend due to the divergence of collections as in-group associates and out-group adherents will grow undesirable ideas about the other congregation. In this concept, when workers are ostracized, they probably distinguish themselves to be less exemplary, fit to the out-group and be different from other decision-making members. As part of the out-group, ostracized characters will learn to show that their principles and opinions are unlike others, such as in-group associates. The deteriorated psychological behavior of detested individuals destroys the firm's image (Lustenberger \& Jagacinski 2010). The available literature on OST suggests that repeated acts of OST result in ultimate depression and severe maladaptive behaviors by the workers (Kidwell et al., 2018; Harvey, Stoner, Hochwarter \& Kacmar, 2007). Research on OST suggests that employees' destructive behavior is understandable, response to social OST (Sharma, 2015), and workplace deviance (Ferris et al., 2008; Lustenberger \& Jagacinski, 2010). This deviance may also be in the form of IPC as the workers try to minimize the depression and frustration caused by OST by conflicting with their fellow workers. So, accordingly, it is hypothesized:

Hypothesis 3: Ostracism positively relates to interpersonal conflicts.

Mediating Role of Ostracism between Abusive Supervision and Interpersonal Conflicts: According to self-determination theory, the abused workers feel threatened by their hostile supervisor for suppressing their basic psychological needs. The hostile supervisor ostracizes the individuals by a feeling of terror and menace (Hitlan, Kelly, Schepman, Schneider \& Zarate, 2006). Workers are consequently diverted by this exploitation and lose vigor to fulfill their job description. Fear and depression dominate them. They try to defend their inner stress resulting from ill-treatment from the social environment of their workplace. Thus, isolation further results in undermining employees' extra-role behavior. The employees are attracted to exhibiting destructive behaviors like indulging in conflicts with their co-workers. They feel less worthwhile to invest extra-role efforts and engage in damaging behaviors like IPC. Consequently, the employees fail to deliver the best possible service to their customers, which is detrimental to the organization (Tepper, 2000).

There are numerous studies where OST is considered an interpersonal stressor, and very few consider this construct as a mediator. Fatima, Raja \& Jahanzeb (2017) have conducted a study where OST mediated organizational deviance and job stress. Workplace OST is positively related to employees' negative work behavior (Zhao et al., 2013) that causes stress and frustration. There are very few studies that examined workplace OST as a mediator. Hence, the emphasis of the current examination is to investigate the mediating role of OST. Ultimately, abused and ostracized workers lack absorption and passion for completing a task efficiently. Threatened by the hostile supervisor, ostracized workers tend to use their energies against the organization by indulging in IPC with the workers. Hence, the author argues; that ABS creates the feeling of OST in individuals which leads to IPC in an organization. So based on these arguments, it is further hypothesized:

Hypothesis 4: Ostracism fully mediates the positive effect of abusive supervision on interpersonal conflicts.

The Moderating Role of Narcissist Personality: Holtzman et al. (2010) have defined the NAR as grandiosity, interpersonal abuse, empathic difficulties, and a sense of entitlement. Due to the bipolar nature of narcissism, it is equally fascinated by common men and classical researchers. On the one hand, narcissists exhibit social behavior that is likely to be a positive aspect. On the other hand, they also exhibit selfish and inconsiderate behaviors that ultimately put them into conflict (Holtzman et al., 2010). Hence, according to the 
contradictory shared concerns, narcissists are categorized as "disagreeable extroverts" (Watson, 2012). As discussed earlier, contradictory characteristics of the narcissist are defined by various scholars, like Back, Kufner, Dufner, Gerlach, Rauthmann, and Denissen (2013) have developed the "Narcissistic Admiration and Rivalry Concept" (NARC). This concept successfully explains the two contradictory civic schemes by which narcissists' impressive self-visions can be preserved extrovert, assertive, and self-enhanced behavior (narcissistic admiration) and the predisposition for incompatible self-preservation, arrogant behavior (narcissistic rivalry).

It is evident from the researches that narcissist admiration is destructively linked to the inclination to privacy, while narcissistic rivalry is positively related to preferences for solitude. Hence, accordingly, the author can argue that "people high in narcissistic admiration have a higher desire to spend time with people around. Conversely, people high in narcissistic rivalry have a low desire to spend time with people; rather, they feel happy spending time with themselves" (Fatfouta et al., 2017). Based on the above reasoning, a narcissistic personality will moderate the relationship negatively between OST and IPC. By communicating with people and raising a voice against abusive supervisors, narcissists can make a difference (Levi \& Bachar, 2019; Watson, 2012). Because people high in narcissistic admiration have high self-esteem, so they confront the OST caused due to hostile supervisors in much better and healthy social views and minimize the damage caused by this hostility (Moeller, Crocker, \& Bushman, 2009). So it is hypothesized: Hypothesis 5a: Narcissism moderates the positive effect of abusive supervision and ostracism such that positive relationship is weaker when employees have high narcissist admiration rather than low. Hypothesis 5b: Narcissism moderates the positive effect of ostracism and interpersonal conflicts such that positive relationship is weaker when employees have high narcissist admiration rather than low.

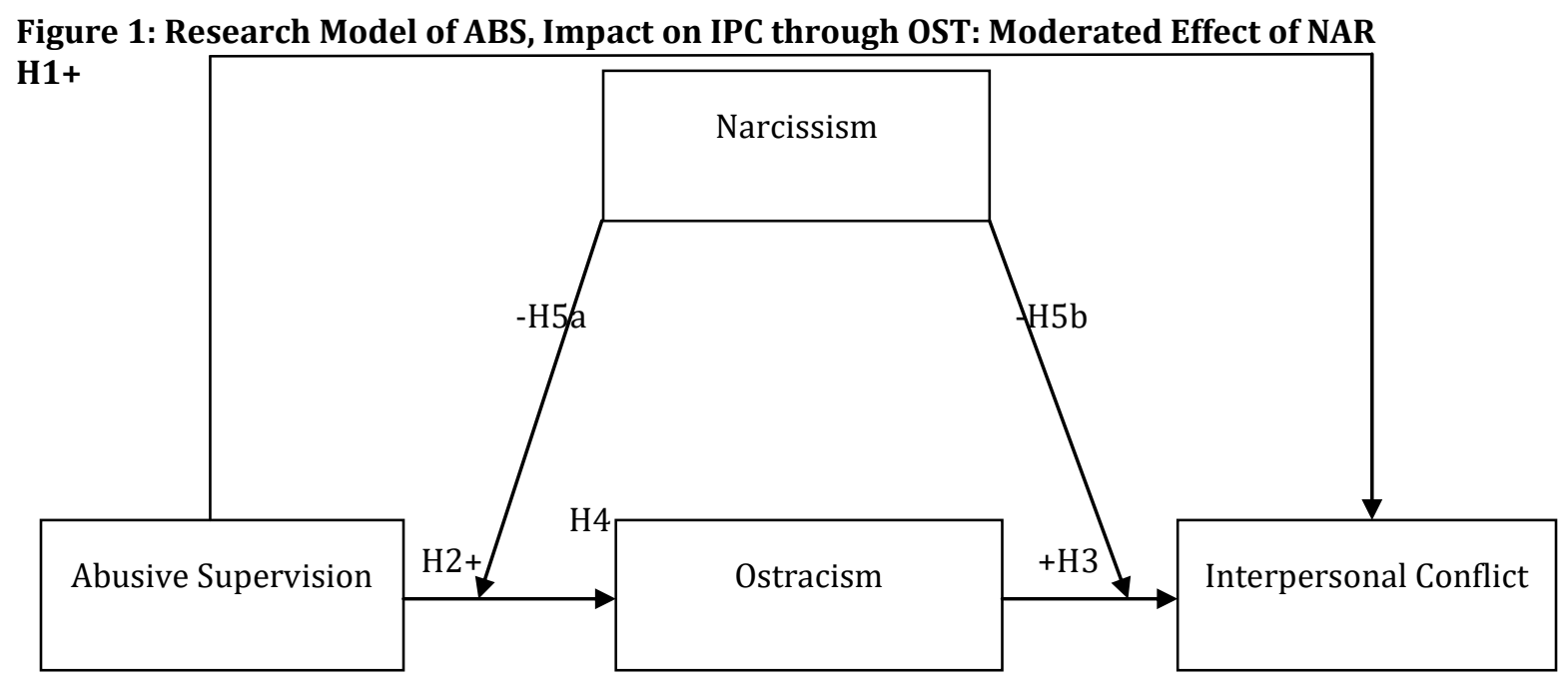

\section{Methodology}

Sampling Design \& Procedures: The author has collected data from the objective employees of private and commercial division banks of Pakistan. By using a convenient sampling technique, the author distributed 650 opinion polls. Out of 650 opinion polls, the author has considered 247 valid responses for analysis. The feedback rate for these 247 reliable replies was 38\%. To expand the feedback proportion, the author deliberated the bank staff as non-respondents if they did not retort despite a couple of follow-up appointments and three prompt calls. Fey and Denison (2003) have used a similar method of data collection. The questionnaire delivered to the respondents consisted of two sections: section 1 encompassed demographic and structural appearances of the respondents, and section 2 consisted of the concepts of the study to be examined.

Measures: To measure and quantify abusive supervision, the author has used a 15 item scale established by Tepper (2000). This scale was previously used in a study by Aryee, Chen, Sun, and Debrah (2007) and demonstrated scale reliability and validity. The reactions were attained through 5 points Likert scale ranging 
from 1=strongly disagree to 5 =strongly agree. (Sample item: My supervisor ridicules me). Assessing narcissism, the author has used the "Narcissistic Admiration and Rivalry Questionnaire" (NARQ; developed by Back et al. (2013). The NARQ includes 18 items that include 9 items measuring individual differences in narcissistic admiration (Sample item: I am great), excluding the 9 items of narcissistic rivalry as the author has studied only one dimension i.e. narcissism admiration. All items were rated on 6 points Likert scale 1= Not agree at all to $6=$ Agree.

Fatfouta et al. (2017) have confirmed the NARQ scale's validity and reliability in a recent study. The author computed Ostracism by a 13 item scale developed by Ferris et al. (2008). The author has recorded the response by a seven-point Likert scale ranging from $1=$ Never to $7=$ Always. Ferris et al., (2008) verified workplace OST to be a uni-dimensional factor structure. This scale has been used in several recent and old studies and demonstrated its reliability and validity. It was used by Leung, $\mathrm{Wu}$, Chen, and Young (2011) and by Gkorezis and Bellou (2016). (Sample item: People ignore me at work). Finally, a 4 item scale, developed by Spector and Jex (1998), was used to enumerate interpersonal conflicts. Responses were documented by the author using a 6-point Likert-scale that ranged from $1=$ Never to $6=$ extremely often. Mulki, Jaramillo, and Locander (2006) have confirmed the validity and reliability of this scale. (Sample item: I get into arguments with others at work).

\section{Results and Discussion}

Table 3 shows descriptive statistics, bivariate correlations, and alpha reliabilities. Table 4 represents the results of the regression analysis. Hypothesis 1 states that ABS is positively related to IPC. Results supported this relationship and found that ABS was positively related to IPC, as indicated by the correlation outcomes showed in table 3 . ABS had a positive and highly significant relationship with IPC (.246**), also the regression coefficient in table 4 strengthens the above statement $(\beta=.334, p<.05)$. This result supports the current study, revealing an increase in ABS will ultimately increase IPC, supporting hypothesis 1 . A previous study has also supported the results, where the abusive supervisor confronts a stronger resistance and interpersonal conflicts of subordinates. Ultimately, it results in work and family conflicts (Tepper, 2000; $\mathrm{Al}$ Hawari et al., 2020; Williams \& Nida, 2011). Hypothesis 2 states that ABS is positively related to OST, which is also supported by the results, as the correlation coefficient for this relationship is $\left(.454^{* *}\right)$ also indicated by the regression coefficient $(\beta=.455 . p<0.05)$. This relationship is confirmed by a recent study where ABS is positively associated with perceived OST (Wang et al., 2020; Ambrose \& Ganegoda 2020).

Similarly, hypothesis 3 was also supported by the results, as the correlation coefficient is $\left(.395^{* *}\right)$ and regression coefficient $(\beta=.536, \mathrm{p}<0.05)$ confirming that OST is positively related to IPC (Ashforth \& Mael 1989; Barki \& Hartwick, 2004). Ferris et al. (2008) also discovered a similar relationship between OST and workplace deviance, more likely in the form of disputes and conflicts among co-workers. Hypothesis 4 states that OST mediates the relationship between ABS and IPC. A four-step linear regression analysis, based on Baron and Kenny's (1986) method, was used to check this relationship. In the first step, ABS was regressed with IPC, and the relationship was significant $(\beta=.334, p<.05)$. In the second step, the author regressed ABS with OST, and the relationship here was also significant $(\beta=.455, \mathrm{p}<0.05)$. In the third step, OST was regressed with IPC, and the relationship was significant $(\beta=.536, p<0.05)$. In the fourth and final step, the author performed a hierarchical regression analysis where ABS was regressed with IPC, controlling the impact of OST, resulting in a significant impact $(\beta=.484, \mathrm{p}<.05)$. The coefficient beta after controlling the mediating variable was low. Hence, according to hypothesis 4, OST will mediate the relationship between ABS and IPC. Fatima et al. (2017) have confirmed the mediation role of OST, where OST mediated between organizational deviance and job stress.

Table 3: Descriptive Statistics, Reliabilities, and Correlations among Variables

\begin{tabular}{lcccccc}
\hline Constructs/variables & Mean & SD & & $\mathbf{1}$ & $\mathbf{2}$ & $\mathbf{3}$ \\
\hline 1 Abusive Supervision & 3.59 & 0.73 & $(0.92)$ & & $\mathbf{4}$ \\
2 Narcissism & 3.48 & 0.71 & $(0.89)$ & & \\
3 Ostracism & 3.35 & 0.73 & $.454^{* *}$ & $(0.88)$ & $0.395^{* *}$ \\
4 Interpersonal Conflict & 3.41 & 0.91 & $.246^{* *}$ & & $(0.88)$ \\
\hline
\end{tabular}


Table 4: Regression Analysis for Mediation

\begin{tabular}{|c|c|c|c|c|c|c|}
\hline & \multirow[b]{2}{*}{ B } & \multicolumn{2}{|c|}{ Ostracism } & \multicolumn{2}{|l|}{ IPC } & \multirow[b]{2}{*}{$\Delta \mathbf{R}^{2}$} \\
\hline & & $\mathbf{R}^{2}$ & $\Delta \mathbf{R}^{2}$ & B & $\mathbf{R}^{2}$ & \\
\hline \multicolumn{7}{|c|}{ Predictors } \\
\hline \multicolumn{7}{|c|}{ Direct effects } \\
\hline \multicolumn{7}{|c|}{ Step 1} \\
\hline $\mathrm{ABS}$ & $0.455^{*}$ & .206 & $.206^{*}$ & $0.334^{*}$ & 0.060 & \\
\hline \multicolumn{7}{|c|}{ Indirect effect } \\
\hline \multicolumn{7}{|c|}{ Step 1} \\
\hline OST & & & & $0.536^{*}$ & .156 & \\
\hline \multicolumn{7}{|c|}{ Step 2} \\
\hline ABS & & & & $.484 *$ & .162 & 0.006 \\
\hline
\end{tabular}

Notes: $\mathrm{N}=247^{*} \mathrm{p}<0.05$

Moderation Analysis: To test the moderation effects of a variable; two-three steps of hierarchical multiple regression methods have been used. Cohen, West, and Aiken (2003) have prescribed this regression method. There are no control variables in the current study. The dependent variable was regressed with a demographical variable to control its effects. The author then added the independent variable in the regression equation, and an interaction term was created by multiplying the independent and moderating variables. The author then entered the values in the regression equation to find the incremental increase in the variance. A significant regression coefficient linked with the interaction term represents the moderating effect of the selected variable. To interpret the interaction model in detail, the author has plotted the threeway interaction of variables. The author has plotted the relationship between ABS and OST at a high and a low level of NAR according to the recommendations of Aiken, West, and Reno (1991). A quick and visual indication of three-way interaction is being provided by figure 1 that signifies the angle between two lines, specifying that the relationship between ABS and OST is strong when an employee had low NAR than when he had high NAR. Consequently, a weaker relationship between ABS and OST at higher NAR was confirmed (Valle et al., 2018). Table 5 \& 6 incorporates moderation results.

Table 5: Moderated Regression Analyses (Model 1)

\begin{tabular}{lccc}
\hline & & OST & \\
Predictor & $\mathbf{B}$ & $\mathbf{R}^{\mathbf{2}}$ & $\mathbf{\Delta R}^{\mathbf{2}}$ \\
\hline Step 1 & & & \\
ABS & $0.478^{*}$ & & \\
NAR & $-0.189^{*}$ & & \\
Step 2 & & & \\
ABS $\times$ NAR & $-0.307^{*}$ & 0.294 & 0.055 \\
\hline
\end{tabular}

Notes: $\mathrm{N}=247 .{ }^{*} \mathrm{p}<.05$ 


\begin{tabular}{l} 
Journal of Economics and Behavioral Studies (ISSN: 2220-6140) \\
Vol. 12, No. 6, pp. 43-58, December 2020 \\
\hline \hline
\end{tabular}

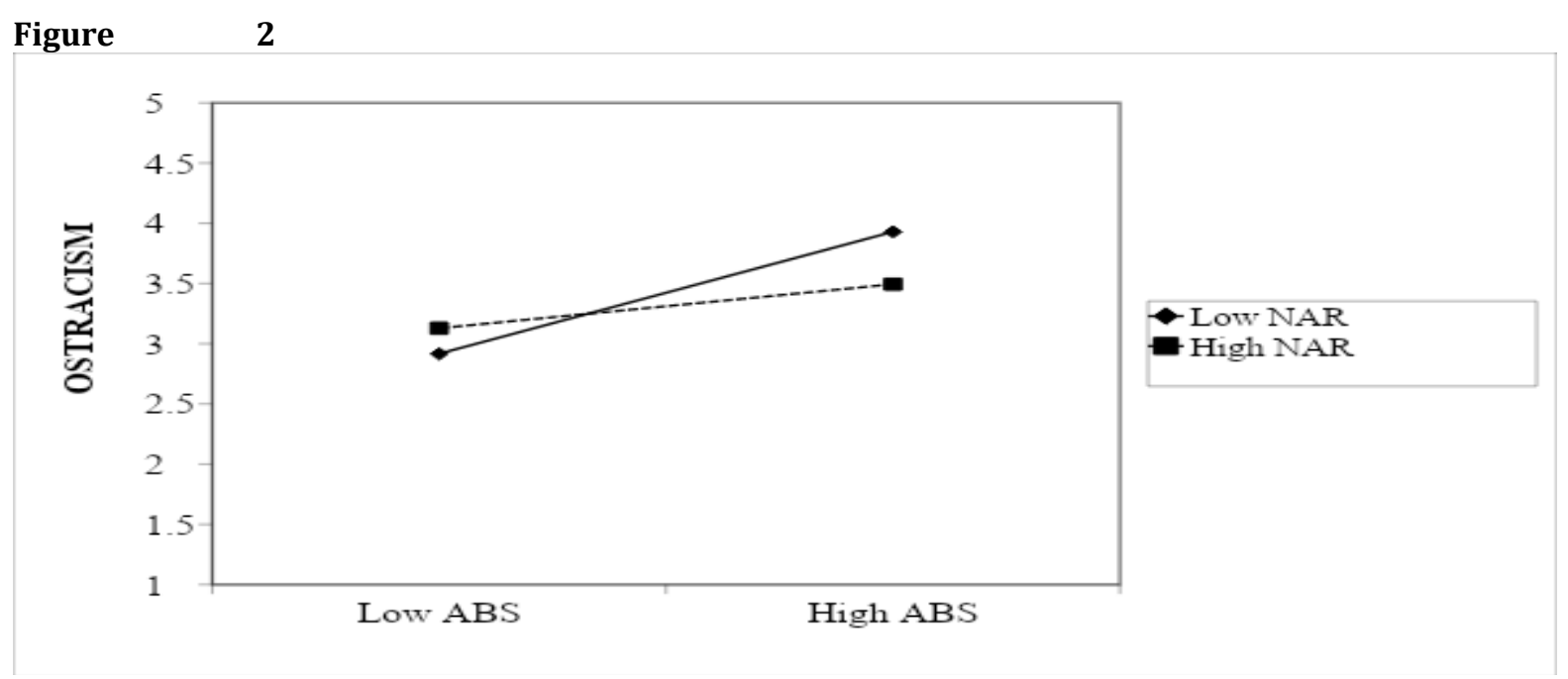

The above graph shows that the relationship between ABS and OST is strong and significant for employees who are lower on NAR (Fatfouta et al., 2017). The relationship loses strength for employees high on NAR. Figure 2 shows that before the point of intersection, the relationship between ABS and OST is strong at a higher NAR. But after the interaction, this relationship becomes weaker at higher NAR. This interaction pattern is consistent with hypothesis 5 a that is, ABS is more positively related to OST when NAR is low but is less positively linked to OST when NAR is high.

Table 6: Moderated Regression Analyses (Model 2)

\begin{tabular}{lccc}
\hline Predictor & $\mathbf{B}$ & $\mathbf{I P C}$ & $\mathbf{\Delta R}^{\mathbf{2}}$ \\
\hline Step 1 & & $\mathbf{R}^{\mathbf{2}}$ & \\
OST & $0.515^{*}$ & & \\
NAR & $-0.167^{*}$ & & \\
Step 2 & & & \\
OST $\times$ NAR & $-0.23^{*}$ & 0.225 & 0.055 \\
\hline Note N $247 \cdot *<.05$ & & & \\
\hline
\end{tabular}

Notes: $\mathrm{N}=247 .{ }^{*} \mathrm{p}<.05$

Likewise, the stated conditions of moderation are evident in Tables 5 and 6 . The moderation results show that NAR moderates the positive relation of ABS and OST and OST and IPC. The employee exhibit contradictory work behavior, OST, due to stress created under an abusive supervisor; ultimately, they are likely to release their frustration on their fellow workers resulting in a skirmish situation in the form of IPC. The results confirm that if the subordinate is a narcissistic personality, he will handle the situation well due to high self-efficacy and self-confidence. Hence, a person having narcissistic admiration qualities will moderate negatively $(\mathrm{B}=-0.307, \mathrm{P}<0.05)$ the positive relation of $\mathrm{ABS}$ and OST, reducing the contradictory work behavior in organizations (Levi \& Bachar 2019; Valle et al., 2018). Likewise, NAR moderates the relationship between OST and IPC $(B=-0.230, \mathrm{P}<0.05)$. Employees defying ABS are inclined to display OST. As OST is nonpredictable comportment, it provokes workforces with innovative tasks and perceptions; hence team workers necessitate sustenance from governance to defy the existing state of affairs (Holtzman et al., 2010). Narcissist admiration and narcissist rivalry are two characters of narcissism; the author has examined the moderated impact of only narcissist admiration on the current model with the worker's perspective. 
Figure 3

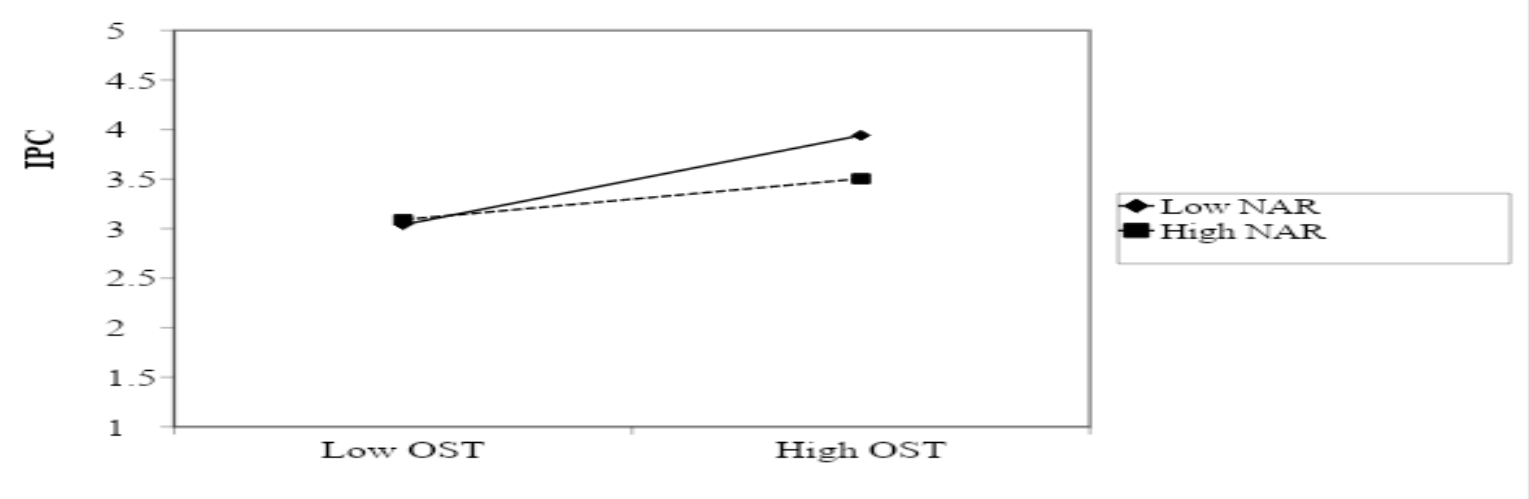

The above graph shows a significant, positive, and strong relationship between OST and IPC when NAR is lower. On the other hand, the relationship between OST and IPC is weaker when NAR is higher. The angle between the two lines is greater when employees had lower NAR. Hence, figure 3 shows the relationship between OST and IPC is weaker at high NAR. The above interaction is consistent with H5b, i.e. OST is more positively linked to IPC when NAR is lower but is less positively related to OST when NAR is higher.

Moderating Role of Narcissism: In the perspective of innovativeness, supervisors demonstrating ABS threaten and challenge the status quo. It may express psychological anxiety and frustration in workforces to disagree with their supervisor and speak out about novel methods of accomplishing work activities. Consequently, in the context of organizational citizenship behavior, circumstantial aspects play a substantial role in encouraging personnel to exhibit extra-role behavior (Ferris et al., 2014). One feature is the workers' association with their supervisor that openly connects with the team worker's state of mind. Hence, with compassionate and supportive management, workers avoid contrary thinking like OST and IPC and willing to take risks to complete tasks assigned by the administration (Ferris et al., 2014; Williams \& Nida, 2011). Furthermore, employees with high narcissistic admiration qualities have very high self-esteem. Due to the high self-efficacy personality trait, a narcissist worker will demonstrate more ethical behavior than a worker with low self-esteem and high narcissistic rivalry traits.

The author has examined the moderating role of narcissistic admiration so; a worker with high narcissistic admiration shows more ethical work behavior and does not indulge in any counter-productive activity like OST or IPC. Therefore a narcissist perceives more support from their supervisor and does not take his supervisory commands as hostile behavior. Narcissist employees often convince their supervisors to consider workers' views in organizational decisions, use rewards and benefits to encourage ethical work behavior, improve their autonomy (Greenbaum et al., 2017), show apprehension for their staff, and accept their mistakes (Ferris et al., 2014). Such governance directs indications about what is essential and guides behavior (Valle et al., 2018). Employees with narcissistic admiration traits cultivate novel work means that show expansion and enhancement in performing diverse activities (Reina et al., 2014). Hence, NAR moderates negatively the positive relationship between ABS and OST as well as OST and IPC. Fig 2 and Fig 3 showed that NAR moderated the ABS and OST relationships and OST and IPC relationships.

\section{Discussion}

The results designate that $A B S$ is positively correlated to IPC $(B=0.246, P<0.05)$ and OST $(B=0.455, P<0.05)$. While OST is also positively related to IPC $(B=0.454, P<0.05)$, and OST mediate liaison between ABS and IPC. In regression analysis for mediation, the independent variable $A B S$, when regressed with the dependent variable, IPC, resulted in statistically significant results $(B=0.334, \mathrm{P}=0.05)$. Additionally, the independent variable $A B S$ regressed with the mediator of the present study OST also yielded significant results $(B=0.536$, $\mathrm{P}<0.05$ ). While when the author regressed the dependent variable IPC on independent variable ABS and mediating variable OST, the mediator OST generated a significant impact on the dependent variable $(\mathrm{B}=$ $0.484, \mathrm{P}=0.001)$, and the independent variable $\mathrm{ABS}$ became an insignificant predictor $(\mathrm{B}=0.114, \mathrm{P}=0.205)$ to 
show the full mediation. Similarly, in moderation analysis, NAR moderates the positive relationship between ABS and OST such that positive association is weaker when staffs have extraordinarily high narcissist admiration rather than low. The results of the interaction term are significantly proving moderation. The incremental increase in the variance explained with the addition of an interaction term shows the moderated effect of NAR. As the regression coefficient associated with the interaction term is significant.

It shows the moderating effects of the selected variable $(B=-0.307, P<0.05)$. Similarly, the regression coefficient associated with the interaction term two is also significant $(B=-0.230, P<0.05)$, representing the moderating effect of NAR on the relationship between OST and IPC such that it weakens the positive relationship between them. Hence, NAR negatively moderates and weakens the positive relation of ABS-OST as well as OST-IPC. ABS employs psychologically damaging impacts on workers' emotional, attitudes, spiritual and physical health. It is inappropriate interpersonal behavior that creates emotionally tense organizational behaviors and crucial interpersonal relations of workers. An offensive supervisor threatens three psychological needs of employees. First, the supervisor's belittle behavior reduces the worker's ability to complete a task effectively. Thus, suppressing workers' sense of competence. Second, abused workers' sense of relatedness is reduced by humiliating and degrading them in front of others as they are not respected members of the organization. Third, the workers behave according to the aspiration of the hostile supervisor to minimize the demean situation. Hence, the subordinates' autonomy is damaged.

\section{Conclusion and Recommendations}

This study revealed a statistically significant and positive impact of ABS on IPC and uncovered a relatively stronger relationship between ABS and IPC. The author found that dis-satisfied psychological needs result in emotional instability and frustration in workers, such as aggression and behavioral deregulation. Ultimately the deprived, frustrated, and abused subordinates are likely to show more controversial behavior like OST. Thus, suppressing the psychological needs of individuals and resulting in the isolation of the workers. Furthermore, this study concluded that due to higher self-esteem conceited individuals are motivated to show less OST, hence are less likely to indulge in IPCs at the workplace. The results also confirmed a positive relationship between OST and IPC. It has been revealed that an increase in OST leads to an increase in IPC.

Additionally, the author has also achieved the objective of checking OST as a mediating variable as results endorsed full mediation of OST between ABS and IPC. In context with narcissism, employee-facing ABS will confront OST differently. NAR admiration employee is more social than NAR rivalry. A narcissistic subordinate will positively deal with ABS and will not ostracize himself as he is people-loving by nature. Ultimately, a narcissist weakens the relationship between ABS and OST and the relationship between OST and IPC. Therefore, it is pertinent and consistent with the results of this study that narcissistic individuals tend to reduce the possibility of IPC because they are high in self-esteem and can deal with the situation accordingly. Hence, the author concluded that NAR moderated the positive relationship between ABS and OST and NAR weakens the positive relationship between OST and IPC.

Theoretical Implications in Organizations: The current research has many contributions to the existing body of knowledge. First, the author has conceptualized the consequences of ABS on OST and IPC. The outcomes of ABS on OST and IPC were missing in the literature in the banking sector. The findings of the present study have confirmed the effect of ABS on OST and IPC. Second, the author has conceptualized how ABS was linked to IPC by examining the mediation of OST. The findings confirmed the mediation mechanism of OST between ABS and IPC. Fourth, the author has conceptualized how NAR moderated the relationship between ABS and OST; and the relationship between OST and IPC. The findings of the current study showed a strong relationship between ABS and OST and between OST and IPC when there was a lower NAR. Conversely, the author also found that the relationship between ABS and OST and between OST and IPC was weaker when there was a higher NAR. The current study addressed a need for researchers to evaluate competing theories about what intervening variables are required to explain the process of OST predicting IPC and other outcomes.

Recommendations: The current study recommends that commercial banks of Pakistan should take corrective measures to decrease the manifestation of supervisory maltreatment. This study has suggested 
several paths by which organizations can minimize supervisory mistreatment. First, the supervisory style should be taken into consideration when recruiting and selecting supervisors. Human resource managers have an immense responsibility for this insight. Second, emotional management training should be encouraged for developing interpersonal skills for the supervisors. The current study found that abusive supervision is one of the antecedents of interpersonal conflict and ostracism in organizations. Mistreatment by the supervisors and their hostile behavior may lead to discomfort among individuals. Therefore, the author suggests designing training programs for supervisors to prevent abusive supervision before it can cause an adverse work environment like IPC and OST. The current research is helpful to understand that ABS leads to OST, which results in IPC. So CEOs and management professionals can use these findings to improve and manage good working relations among workers and management. The current examination addresses the importance of a decent relationship to expand and maintain the desired productivity.

The current study provides implications for managers, as it brings attention to other factors impacting ABS. As perceived deep-level divergence is an essential originator of ABS, it is of great significance for organizations to decline such perception by enlightening diversity, considering trait empathy when recruiting managers and providing justice training for supervisors. By doing so, supervisors are more likely to be stimulated to accept and embrace divergent values and may develop empathy to interact equally with both similar and dissimilar employees. As a result, those well-trained supervisors may not confine their justice scopes narrowly and are less likely to execute ill-treatment to employees who are perceived to be divergent. This cognitive of managing supervisors will result in managing the workforce to reduce OST. Ultimately IPC can be minimized as well. Hence, according to the current study, lower ABS leads to lower IPC and OST. Finally, based on the current study findings, the author recommends developing the narcissism admiration dimension to the personality of employees during the recruitment and training process. There are positive and negative outcomes of healthy and unhealthy narcissism and negative outcomes should not be ignored by the companies.

Limitations and Future Research: Like any study, this study has some limitations. Future researchers can increase the sample size. Private \& government banking sector employees and employees with short-term contracts should be included as a sample to compare the difference. Due to self-report measures, socially desirable answers increase the chances of biases in reporting. Another gross limitation of the study is that usually, people respond in a socially desirable way. The element of social desirability might be causing hurdles to the actual findings of the study. Building on the boundaries of the present research work, the author suggests the future scholars replicate the study to different personality frameworks. For example, scholars can study ABS and its consequence in the Big Five personality domains rather than narcissistic personalities. The supervisor's Machiavellianism may be another ground to be studied in the context of the present study. Moreover, this study has only inspected the NAR of the subordinate in the form of narcissist admiration. Future scholars are encouraged to study the other dimensions of NAR, such as narcissist rivalry for the supervisor and the subordinate. There is also a need to encourage future scholars to measure the construct of ABS critically.

\section{References}

Aiken, L. S., West, S. G. \& Reno, R. R. (1991). Multiple regression: Testing and interpreting interactions (8 $8^{\text {th }}$ ed), Sage. London: Sage Publications.

Al-Hawari, M. A., Bani, M. S. \& Quratulain S. (2020). Do frontline employees cope effectively with abusive supervision and customer incivility? Testing the effect of employee resilience. Journal of Business and Psychology, 35(2), 223-240.

Ambrose, M. L. \& Ganegoda, D. B. (2020). Abusive according to whom? Manager and subordinate perceptions of abusive supervision and supervisors' performance. Journal of Organizational Behavior, 41(8), 737756.

Aryee, S., Chen, Z. X., Sun, L. Y. \& Debrah, Y. A. (2007). Antecedents and outcomes of abusive supervision: Test of a trickle-down model. Journal of Applied Psychology, 92(1), 191.

Ashforth, B. E. \& Mael, F. (1989). Social identity theory and the organization. Academy of management review, 14(1), 20-39. 
Back, M. D., Küfner, A. C., Dufner, M., Gerlach, T. M., Rauthmann J. F. \& Denissen, J. J. (2013). Narcissistic admiration and rivalry: Disentangling the bright and dark sides of narcissism. Journal of Personality and Social Psychology, 105(6), 1013.

Barki, H. \& Hartwick, J. (2004). Conceptualizing the construct of interpersonal conflict. International journal of conflict management, 15(3), 216-244.

Baron, R. M. \& Kenny, D. A. (1986). The moderator-mediator variable distinction in social psychological research: Conceptual, strategic, and statistical considerations. Journal of personality and social psychology, 51(6), 1173.

Carson, J. E., Hoobler, J. \& McAllister, C. P. (2017). Abusive Supervision and Subordinate Self-Control: Implications for Social Exchange. Academy of Management Proceedings, Academy of Management Briarcliff Manor, NY 10510.

Cohen, J. P., West, S. G. \& Aiken, L. S. (2003). Applied multiple regression/correlation analysis for the behavioral sciences, Mahwah, NJ: Erlbaum, 174(4), 1052454.

Cheshure, A., Zeigler, H. V. \& Sauls, D. (2020). Narcissism and emotion deregulation: Narcissistic admiration and narcissistic rivalry have divergent associations with emotion regulation difficulties. Personality and Individual Differences, 154, 109679.

Deci, E. L. \& Ryan, R. M. (2011). Self-determination theory. Handbook of theories of social psychology, 1(2011), 416-433.

Dong, Y., Wen, W., Zhang, D. \& Fang, Y. (2020). The relationships between narcissistic admiration, rivalry, and interpersonal trust in adolescents: The mediating effect of ostracism experience. Children and Youth Services Review, 105521.

Derfler-Rozin, R., Pillutla, M. \& Thau, S. (2010). Social reconnection revisited: The effects of social exclusion risk on reciprocity, trust, and general risk-taking. Organizational Behavior and Human Decision Processes, 112(2), 140-150.

Fatfouta, R., Zeigler-Hill, V. \& Schröder-Abé, M. (2017). I'm merciful, am I not? Facets of narcissism and forgiveness revisited. Journal of Research in Personality, 70, 166-173.

Fatima, T., Raja, U. \& Jahanzeb, S. (2017). A Moderated Mediation Model of Ostracism, Psychological Capital, Need Frustration and Deviance. Academy of Management Proceedings, Academy of Management Briarcliff Manor, NY, 10510.

Ferris, D. L., Brown, D. J. Berry, J. W. (2008). The development and validation of the Workplace Ostracism Scale. Journal of Applied Psychology, 93(6), 1348.

Ferris, D. L., Lian, H. Brown, D. J. \& Morrison, R. (2014). Ostracism, self-esteem, and job performance: When do we self-verify and when do we self-enhance? Academy of Management Journal, 58(1), 279-297.

Fey, C. F. \& Denison, D. R. (2003). Organizational culture and effectiveness: can American theory be applied in Russia? Organization Science, 14(6), 686-706.

Furnham, A., Richards, S. C. \& Paulhus, D. L. (2013). The Dark Triad of personality: A 10-year review. Social and Personality Psychology Compass, 7(3), 199-216.

Gardner, W. L., Pickett, C. L., Jefferis, V. \& Knowles, M. (2005). On the outside looking in Loneliness and social monitoring. Personality and Social Psychology Bulletin, 31(11), 1549-1560.

Gkorezis, P. \& Bellou, V. (2016). The relationship between workplace ostracism and information exchange: The mediating role of self-serving behavior. Management Decision, 54(3), 700-713.

Greenbaum, R. L., Mawritz, M. B. \& Quade, M. J. (2017). Employee Machiavellianism to unethical behavior: The role of abusive supervision as a trait activator. Journal of Management, 43(2), 585-609.

Haggard, D. L., Robert, C. \& Rose, A. J. (2011). Co-rumination in the workplace: Adjustment trade-offs for men and women who engage in excessive discussions of workplace problems. Journal of Business and Psychology, 26(1), 27-40.

Harvey, P., Stoner, J., Hochwarter, W. \& Kacmar, C. (2007). Coping with abusive supervision: The neutralizing effects of ingratiation and positive effect on negative employee outcomes. The Leadership Quarterly, 18(3), 264-280.

Hitlan, R. T., Kelly, K. M., Schepman, S., Schneider, K. T. \& Zárate, M. A. (2006). Language exclusion and the consequences of perceived ostracism in the workplace. Group Dynamics: Theory, Research, and Practice, 10(1), 56.

Holtzman, N. S., Vazire, S. \& Mehl, M. R. (2010). Sounds like a narcissist: Behavioral manifestations of narcissism in everyday life. Journal of Research in Personality, 44(4), 478-484. 
Kidwell, R. E., Eddleston, K. A. \& Kellermanns, F. W. (2018). Learning bad habits across generations: How negative imprints affect human resource management in the family firm. Human Resource Management Review, 28(1), 5-17.

Kluemper, D. H., Mossholder, K. W., Ispas, D., Bing, M. N., Iliescu, D. \& Ilie, A. (2018). When Core SelfEvaluations Influence Employees' Deviant Reactions to Abusive Supervision: The Moderating Role of Cognitive Ability. Journal of Business Ethics, 1-19.

Kohli, R. K. \& Mitchell, F. (2007). Working with unaccompanied asylum-seeking children: issues for policy and practice, Macmillan International Higher Education.

Krasikova, D. V., Green, S. G. \& LeBreton, J. M. (2013). Destructive leadership: A theoretical review, integration, and future research agenda. Journal of Management, 39(5), 1308-1338.

Lam, C. K., Walter, F. \& Huang, X. (2017). Supervisors' emotional exhaustion and abusive supervision: The moderating roles of perceived subordinate performance and supervisor self-monitoring. Journal of Organizational Behavior, 38(8), 1151-1166.

Leary, M. R., Tambor, E. S., Terdal, S. K. \& Downs, D. L. (1995). Self-esteem as an interpersonal monitor: The sociometer hypothesis. Journal of personality and social psychology, 68(3), 518.

Leung, A. S., Wu, L., Chen, Y. \& Young, M. N. (2011). The impact of workplace ostracism in service organizations. International Journal of Hospitality Management, 30(4), 836-844.

Levi, E. \& Bachar, E. (2019). The moderating role of narcissism on the relationship between posttraumatic growth and PTSD symptoms. Personality and Individual Differences, 138, 292-297.

Lustenberger, D. E. \& Jagacinski, C. M. (2010). Exploring the effects of ostracism on performance and intrinsic motivation. Human Performance, 23(4), 283-304.

Mackey, J. D., Frieder, R. E., Brees, J. R. \& Martinko, M. J. (2017). Abusive supervision: A meta-analysis and empirical review. Journal of Management, 43(6), 1940-1965.

Malik, O. F., Shahzad, A. \& Waheed, A. (2020). Abusive supervision as a trigger of malevolent creativity: do the Light Triad traits matter? Leadership \& Organization Development Journal.

Mitchell, M. S. \& Ambrose, M. L. (2007). Abusive supervision and workplace deviance and the moderating effects of negative reciprocity beliefs. Journal of Applied Psychology, 92(4), 1159.

Moeller, S. J., Crocker, J. \& Bushman, B. J. (2009). Creating hostility and conflict: Effects of entitlement and selfimage goals. Journal of Experimental Social Psychology, 45(2), 448-452.

Mulki, J. P., Jaramillo, F. \& Locander, W. B. (2006). Effects of ethical climate and supervisory trust on salesperson's job attitudes and intentions to quit. Journal of Personal Selling \& Sales Management, 26(1), 19-26.

Pakistan Economic Survey. (2015-2016). Islamabad: Ministry of Finance, Government of Pakistan. 2016. http://www.finance.gov.pk/survey_1516.html.

Reina, C. S., Zhang, Z. \& Peterson, S. J. (2014). CEO grandiose narcissism and firm performance: The role of organizational identification. The leadership quarterly, 25(5), 958-971.

Robinson, S. L., O'Reilly, J. \& Wang, W. (2013). Invisible at work: An integrated model of workplace ostracism. Journal of Management, 39(1), 203-231.

Rudert, S. C., Janke S. \& Greifeneder R. (2020). The experience of ostracism over the adult life span. Developmental Psychology, 56(10), 1999.

Schat, A., Desmarais, S. \& Kelloway, E. K. (2006). Exposure to workplace aggression from multiple sources: Validation of a measure and test of a model. Unpublished manuscript, McMaster University, Hamilton, Canada, 331-351.

Schyns, B., Felfe, J. \& Schilling, J. (2018). Is it me or you? How reactions to abusive supervision are shaped by leader behavior and follower perceptions? Frontiers in Psychology, 9, 1309.

Sharma, R. (2015). Team conflict: Impact and resolution enhancing the success of the organization. Journal Impact Factor, 6(1), 733-739.

Smola, K. \& Sutton, C. D. (2002). Generational differences: Revisiting generational work values for the new millennium. Journal of Organizational Behavior: The International Journal of Industrial, Occupational and Organizational Psychology and Behavior, 23(4), 363-382.

Spector, P. E. \& Jex, S. M. (1998). Development of four self-report measures of job stressors and strain: interpersonal conflict at work scale, organizational constraints scale, quantitative workload inventory, and physical symptoms inventory. Journal of occupational health psychology, 3(4), 356.

State Bank of Pakistan. (2019). Banking statistics of Pakistan. http://www.sbp.org.pk/publications/anu_stats/2019.htm 
Tajfel, H. (2010). Social identity and intergroup relations, Cambridge University Press.

Tepper, B. J. (2000). Consequences of abusive supervision. Academy of management journal, 43(2), 178-190.

Tepper, B. J. (2007). Abusive supervision in work organizations: Review, synthesis, and research agenda. Journal of Management, 33(3), 261-289.

Valle, M., Kacmar, K. M., Zivnuska, S. \& Harting, T. (2018). Abusive supervision, leader-member exchange, and moral disengagement: A moderated mediation model of organizational deviance. The Journal of social psychology, 1-14.

Watson, J. M. (2012). Educating the Disagreeable Extravert: Narcissism, the Big Five Personality Traits, and Achievement Goal Orientation. International Journal of Teaching and Learning in Higher Education, 24(1), 76-88.

Wang, Z., Du, J., Yu, M., Meng, H. \& Wu, J. (2020). Abusive supervision and newcomers' turnover intention: a perceived workplace ostracism perspective. The Journal of General Psychology, 1-16.

Williams, K. D. \& Nida, S. A. (2011). Ostracism: Consequences and coping. Current Directions in Psychological Science, 20(2), 71-75.

Wu, L. Z., Yim, F. H. k., Kwan, H. K. \& Zhang, X. (2012). Coping with workplace ostracism: The roles of ingratiation and political skill in employee psychological distress. Journal of Management Studies, 49(1), 178-199.

Yagil, D. (2006). The relationship of service provider power motivation, empowerment and burnout to customer satisfaction. International Journal of Service Industry Management, 17(3), 258-270.

Zhang, L., Xie, Y., Xue, W. \& Xu, X. (2020). The challenges and countermeasures of blockchain in finance and economics. Systems Research and Behavioral Science, 37(4), 691-698.

Abusive supervision, thwarted belongingness, and workplace safety: A group engagement perspective. Journal of Applied Psychology, 105(3), 230.

Zhao, H., Peng, Z. \& Sheard, G. (2013). Workplace ostracism and hospitality employees' counterproductive work behaviors: The joint moderating effects of proactive personality and political skill. International Journal of Hospitality Management, 33, 219-227. 